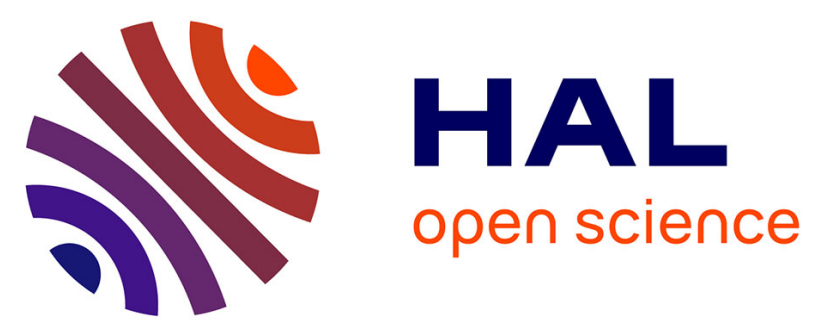

\title{
Experimental and numerical study of the hydraulic jump of an impinging jet on a moving surface
}

\author{
Michel Gradeck, Arsène Kouachi, Adil Dani, David L Arnoult, Jean-Luc
}

Borean

\section{- To cite this version:}

Michel Gradeck, Arsène Kouachi, Adil Dani, David L Arnoult, Jean-Luc Borean. Experimental and numerical study of the hydraulic jump of an impinging jet on a moving surface. Experimental Thermal and Fluid Science, 2006, 30 (3), pp.193-201. 10.1016/j.expthermflusci.2005.05.006 . hal-01579183

\section{HAL Id: hal-01579183 \\ https://hal.univ-lorraine.fr/hal-01579183}

Submitted on 30 Aug 2017

HAL is a multi-disciplinary open access archive for the deposit and dissemination of scientific research documents, whether they are published or not. The documents may come from teaching and research institutions in France or abroad, or from public or private research centers.
L'archive ouverte pluridisciplinaire HAL, est destinée au dépôt et à la diffusion de documents scientifiques de niveau recherche, publiés ou non, émanant des établissements d'enseignement et de recherche français ou étrangers, des laboratoires publics ou privés. 


\title{
Experimental and numerical study of the hydraulic jump of an impinging jet on a moving surface
}

\author{
M. Gradeck ${ }^{1 *}$, A. Kouachi ${ }^{1}$, A. Dani ${ }^{2}$, D. Arnoult ${ }^{3}$ and J.L. Boréan ${ }^{3}$ \\ ${ }^{1}$ LEMTA CNRS UMR 7563 - 2, avenue de la forêt de haye BP160 - F-54504 Vandoeuvre-lès-Nancy Cedex \\ ${ }^{2}$ LIPE- INSA de Toulouse - 135 avenue de Rangueil, F-31077 Toulouse Cedex 4 \\ ${ }^{3}$ ARCELOR Research - Voie Romaine - B.P. 30320 - 57283 Maizière-Lès-Metz Cedex \\ *Corresponding author : michel.gradeck@ensem.inpl-nancy.fr
}

\begin{abstract}
:
The purpose of the present paper is to study experimentally a free impinging axisymmetric jet on a moving surface. Comparisons of the experimental data and the numerical simulations using Star CD software have been made in order to validate the numerical procedure. Since heat transfer efficiency of cooling process is controlled by hydrodynamic field, the first step is to check if numerical results are in agreement with experimental data. The final goal is to simulate the cooling of rolling process in steel making. Experiments have been carried out with tap water and with two nozzle diameters (17 and $20 \mathrm{~mm}$ ).
\end{abstract}

\section{Key words :}

Impinging jet, moving surface, hydraulic jump

\section{Nomenclature}

$D \quad$ nozzle diameter, $(\mathrm{m})$

$D_{\text {simu }}$ corrected nozzle diameter used for numerical simulation, (m)

$g \quad$ acceleration of gravity, $\left(\mathrm{m} / \mathrm{s}^{2}\right)$

$H \quad$ distance between nozzle and the plate, $(\mathrm{m})$

$h_{\text {simu }}$ corrected distance between nozzle and the plate used for numerical simulation, (m)

$\bar{H} \quad$ dimensionless distance, $\left(\frac{H}{D}\right)$ 
$Q \quad$ volumetric flow rate of the liquid jet, $\left(\mathrm{m}^{3} / \mathrm{s}\right)$

$R_{J u} \quad$ radius of the hydraulic jump, (m)

$\overline{R_{j u}} \quad$ dimensionless radius, $\left(\frac{R_{j u}}{D}\right)$

Re Reynolds number of the jet, $\left(\frac{\rho \cdot V_{j} \cdot D}{\mu}\right)$

$V_{I} \quad$ average impact jet velocity, $(\mathrm{m} / \mathrm{s})$

$V j \quad$ average jet exit velocity, $(\mathrm{m} / \mathrm{s})$

$V j_{\text {simu }}$ corrected average jet exit velocity used for numerical simulation, (m/s)

$V_{S} \quad$ velocity of impingement surface, $(\mathrm{m} / \mathrm{s})$

$\overline{V_{S}} \quad$ dimensionless surface velocity, $\left(\frac{V_{S}}{V_{j}}\right)$

We Weber number, $\left(\frac{\sigma}{\rho \cdot V_{j}^{2} \cdot D}\right)$

$\mathrm{x}, \mathrm{y}, \mathrm{z}$ coordinates measured from the impingement point, (m)

$Y_{j u} \quad$ position of the first minimum, (m)

greek letters

$\alpha_{\text {water }}$ volume fraction of water

$\mu \quad$ dynamic viscosity $(\mathrm{kg} / \mathrm{ms})$

$v \quad$ kinematic viscosity $\left(\mathrm{m}^{2} / \mathrm{s}\right)$

$\rho_{\text {water }}$ density of water, $\left(\mathrm{kg} / \mathrm{m}^{3}\right)$

$\rho_{m} \quad$ density of mixture, $\left(\mathrm{kg} / \mathrm{m}^{3}\right)$

$\sigma \quad$ surface tension, $\left(\mathrm{kg} / \mathrm{s}^{2}\right)$ 


\section{Introduction}

Impinging jets are known to ensure high heat and mass transfer coefficients, so these are used in many industrial applications. In steel making, impinging water jets are widely used in rolling processes. In paper making, impinging air jets are also the best way to dry the paper. Experimental, analytical and numerical studies have provided numerous data on free impinging jets, submerged jets or confined jets ; data are most often concerned with heat transfer capabilities of free or submerged impinging jets. The presence of a moving plate results in a much more complicated flow structure, but it is realistic in the potential industrial applications. As the heat and mass transfer beneath an impinging jet depend on the nature of the flow field, full understanding of the flow structure is necessary to understand the associated heat and mass transfer phenomena.

Valuable results on free surface impinging jets can be found in the literature. The theory of film flows is widely described in the precursor works of Watson [1]. Watson found analytically the expression of the velocity fields of the four flow regions [1] using boundary layer theory. He divided the flow radially into a stagnation region, a boundary layer region with surface velocity equal to the jet velocity, a region of decreasing free surface velocity, and lastly a hydraulic jump. So, he expressed the solution in a self similar manner. Nakoryakov et al. [2] discussed Watson's analytical results with their experiments. Azuma and Hoshino [3] experimentally verified Watson's expression for laminar boundary layer, similarity region and film thickness using laser-Doppler measurements. Stevens et al. [4] have compared measurements of the velocity profiles (LDV), layer depth and free surface velocity with analytical predictions. They have shown that the maximum velocity in the layer is not at the free surface for $r / d<2.5$; thus, this invalidated the assumptions of many analytical models for 
this region of the flow. So, for the last three or four decades, film flows have been widely studied ; velocity fields of each region have been found and these can be used to study the convective heat transfer problems [4-6]. Bohr et al. [7] showed that the radius $R_{j u}$ of the jump can be estimated through the scaling relation $R_{j u} \sim Q^{\frac{5}{8}} \cdot v^{-\frac{3}{8}} \cdot g^{-\frac{1}{8}}$ where $Q$ is the volume flow rate, $v$ is the kinematic viscosity and $g$ is the gravitational acceleration.

Despite the great practical importance in cooling of rolled metals, jet impinging on moving surface received much less attention. One can notice the studies of Zumbrunnen et al. [8-9]. In the case of plane jet, they have shown that the moving surface strongly influences the flow field and the heat transfer. The water from the nozzle is divided when it impinges the plate (moving or not); the flow can be opposed or in the direction same as that of plate motion. The transport of the fluid away from the stagnation line can be facilitated by the moving plate. However, on the other side, fluid is entrained and could penetrate again the impingement region (beneath the jet). For axisymmetric water jet impinging a moving plate, the flow structure is much more complicated because the jet divides in all directions, but one can observe the same phenomena of re-entrainment of the fluid. Zumbrunnen [8] solved the Navier-Stokes equations by similarity analysis; the heat and mass transfer distributions were determined by solving numerically the conservation equations for energy and species. He concluded that the influence of the surface motion on fluid flow is confined to a thin region which can be represented by the velocity boundary layer thickness for a plane jet impinging on a stationary surface. Convective heat transfer is unaffected by the surface motion when the surface temperature is constant along the impingement surface. But in the case of a spatially dependent temperature, convective heat transfer is dependent on the dimensionless surface velocity $\bar{V}_{S}$. In most applications using impinging jets, surface temperature decreases in the direction of surface motion. More recently, Chattopadhyay and Saha [10] numerically studied 
the flow field for the impinging of a rectangular submerged jet on a moving surface for moderately high Reynolds number $(\mathrm{Re}=5800)$ using the large eddy simulation technique. They provided a large database of turbulent quantities for such a configuration.

\section{Experimental set-up}

The configuration considered is that of one axisymmetric impinging jet. The fluid used is water at $20^{\circ} \mathrm{C}\left(\rho=1000 \mathrm{~kg} \cdot \mathrm{m}^{-3}\right.$ and $\mu=10^{-3}$ Pa.s $)$. The jet impingement set-up used for the experiments is a transparent closed loop but which is opened to the atmosphere, containing a pump and an electromagnetic flow meter as shown in Fig. 1 . The jet issues at $20^{\circ} \mathrm{C}$ from a 17 $\mathrm{mm}$ (or $20 \mathrm{~mm}$ ) nozzle diameter and impinges on the moving surface perpendicularly.

The moving surface is a plastic strip which is stretched between two rollers. It is stretched enough to prevent deformation by the impact of the water jet. The width of the plastic strip is large enough for the jet expansion but water can flow by the sides. This moving strip is driven by an electric motor and its speed is measured by a tachometer.

\subsection{Hydraulic jump visualisation}

As hydraulic jump is a phenomenon which is supposed to be stationary, there is no need to use videos or high-speed videos. These phenomenon can be easily visualised. At first, a picture "grid" is taken before each experiment. Then, a set of pictures of the impinging jet is recorded. Then, the picture "grid" is superimposed on the photographs. So, the detailed pattern of the hydraulic jump can be easily measured (see Fig. 2). The mesh dimension showed is equal to $1 \mathrm{~cm}$ but another grid whose mesh is equal to $0,5 \mathrm{~mm}$ is available. The 
position of the hydraulic jump is identified in the Cartesian reference frame shown in Fig. 2 using a minimum of 25 points. The origin $O$ of the reference frame is chosen at the centreline of the impinging jet when there is no strip motion. In our conditions, the jet flow is always turbulent so some unstable disturbances can be carried to the film flow. To reduce these effects on the jump position, each experiment is carried several times.

Each experiment refers to one speed of the strip, to a height (distance between the nozzle exit and the moving strip) and to one flow rate (outlet velocity of the jet). Table 1 gives the experimental test conditions.

\section{2 flow simulation}

Release 3.15 of Star CD software has been used for every simulation of impinging jet on the moving strip. In this study, the volume of fluid model (VOF) proposed by Hirt and Nichols [11] was used to calculate the shape of the free surface of water jet impinging on the flat moving plate. The VOF model is designed for two (or more) immiscible fluids. What interests us is to well simulate the position of the interface between the fluids (air and water). In the VOF model, a single set of momentum equation is applied to the fluids. The properties of the mixed fluid are determined by the presence of the component phases in each control volume. The scalar value of $\alpha_{\text {water }}$ is defined by the ratio of the heavy fluid volume to the total fluid volume. The transport equation of the volume of fraction $\alpha_{\text {water }}$ is :

$$
\frac{\partial}{\partial t}\left(\rho_{\text {water }} \cdot \alpha_{\text {water }}\right)+\nabla \cdot\left(\rho_{\text {water }} \cdot \alpha_{\text {water }} \cdot U\right)=0
$$

The global continuity equation for the mixture is : 
$\frac{D}{D t} \rho_{m}+\rho_{m} \nabla U=0$

However, the VOF method requires additional closure equations before it can be applied to turbulent flows. k- $\varepsilon$ turbulence models have proved to be sufficient for many engineering problems. Figure 3a shows the geometry of our interest, the associated boundary conditions and the coordinate systems used in this study. The grid is divided in two main parts : one is the upper part of the moving plate, the other one is the lower part of the nozzle. The grid was refined in close wall in order to correctly treat the two layers model (Wolfshtein model [12] or Norris and Reynolds [13]). In order to reduce the size of the calculation domain, the jet velocity is supposed to be $V j_{\text {simu }}$ instead of $V j$. It exits at $h_{\text {simu }}$ instead of $H$ from a nozzle diameter equal to $D_{\text {simu }}$ instead of $D$. These new parameters are calculated assuming the gravitational acceleration. Finally, the flow is supposed to be symmetric with respect to the symmetry plane (Figure 3).

\section{Numerical procedure}

VOF model is activated in order to track the interface between air and water. As isotropic eddy-viscosity models produce excessive turbulent kinetic energy in impingement regions due to an unrealistic simulation of the normal turbulent stresses. So, the turbulence is modelled assuming a non-linear k- $\varepsilon$ model (quadratic/high Reynolds number) because of the great anisotropy of the flow in the case of impinging jets. This turbulence model has been first associated with the Wolshtein model [12]. This model consists of resolving the viscosityaffected regions (close to wall) with a one-equation model, while the outer core flow is resolved with the $\mathrm{k}-\varepsilon$ model. In this one-equation model, the eddy-viscosity is made proportional to a velocity scale and a length scale. Using a two-layer model, a very fine mesh is then required near the wall. Typically, the cell dimension was $11,4 \mu \mathrm{m}$ which corresponds to 
$z^{+}=\frac{\sqrt{\tau_{w} / \rho . z}}{v}=0,934 ;$ where $\tau_{w}$ is the wall shear stress and $z$ the distance to the wall. As the results of the calculation can be greatly influenced by the grid in the zone close to the wall, we made tests with different grids. One with 15 non-uniform meshes on a $3 \mathrm{~mm}$ thickness, the other one 20 non-uniform meshes on a $3 \mathrm{~mm}$ thickness. For spatial discretization, we tested first a second order MARS scheme (Monotone Advection and Reconstruction Scheme)and an implicit scheme for the temporal discretization (reference case).

\section{Boundary conditions}

The whole domain has been divided in three main parts:

- the velocity inlet $\left(\alpha_{\text {water }}=1\right)$ and the jet nozzle (wall with no slip condition)

- the jet development zone (pressure imposed and no inlet of water)

- the impingement plate (moving wall with no slip $-k=0$ )

In the present paper, three different cases have been simulated (Table 2). These have been chosen for the velocity ratio $\overline{V_{S}}(1.02,1.53$ and 5.1).

\section{Results and discussion}

\subsection{Hydraulic jump position}

In the case of an axisymmetric jet impinging on a static surface, the hydraulic jump will be circular. As Watson [1] demonstrated, the radius of the hydraulic jump can be estimated from different parameters such as $Q, \mathrm{a}, v$ and $\mathrm{g}$. If the impingement surface moves with a constant velocity $V_{S}$, then the hydraulic jump position depends on the velocity ratio $\bar{V}_{S}$ as well. The hydraulic jump's position can be estimated (with 25 points) from visualizations obtained for 
the different test conditions (Fig. 4 and 5). From each hydraulic jump position, two more parameters can be calculated:

- $\quad Y_{j u}:$ position of first minimum

- $\quad R_{j u}$ : radius of jump's curvature at the first minimum

The position of the first minimum is found by approximating the measured points (hydraulic jump) with a polynomial of second order $\left(y=a x^{2}+b x+c\right)$; the first minimum corresponds to the constant $c$ of the polynomial. The radius of curvature of the jump at the first minimum is derived from the polynomial expression (Eq. 3).

$R_{j u}=\frac{\left(1+b^{2}\right)^{1,5}}{a \sqrt{1-b^{2}}}$

This curvature depends on the speed of the moving strip and on the volumetric flow rate of the liquid and its properties. So, $R_{j u}$ is a function of the following type :

$R_{j u}=f\left(\mu, \rho, \sigma, D, H, Q, V_{S}\right)$

According to the Buckingham $\pi$-theorem, the relation Eq. (4) can be written by means of four dimensionless groups.

$$
\frac{R_{j u}}{D}=A\left(\frac{V_{S} \cdot D^{2}}{Q}\right)^{\alpha}\left(\frac{D \cdot \mu}{Q \cdot \rho}\right)^{\beta}\left(\frac{H}{D}\right)^{\gamma}\left(\frac{D^{3} \cdot \sigma}{Q^{2} \cdot \rho}\right)^{\xi}
$$


The groups on the right side of Eq. (5) are respectively the velocity ratio $\bar{V}_{S}$, the Reynolds number, the height ratio $\bar{H}$ and the Weber number. The values of the exponents $\alpha, \beta, \gamma, \xi$ and the proportionality coefficient $A$ have been determined by the least square method. The resulting relationship is as follows :

$\overline{R_{j u}}=1.0033 \cdot{\overline{V_{S}}}^{0,44} \cdot \operatorname{Re}^{0,0073} \cdot \bar{H}^{0,607} \cdot W e^{0,058}$

The calculated dimensionless radius $\overline{R_{j u}}$ versus the measured dimensionless radius is plotted on Figure 6 from which we conclude that equation (6) correlates experimental results satisfactorily. We noted that the deviation of the experimental values to equation (6) not exceeds $\pm 20 \%$. These results are applicable within the following limits of the dimensionless groups:

$\overline{R_{j u}}=1.04-6.64 ; \overline{V_{S}}=0.42-5.1 ; \operatorname{Re}=6800-36900 ; \bar{H}=3.9-8.82 ;$

$W e=0.86 \times 10^{-3}-25.5 \times 10^{-3}$.

\subsection{Numerical results}

The numerical results are compared to the experimental ones in order to validate the numerical procedure. The main problem appears to be the choice of the near-wall treatment and thus the choice of the turbulence model. In our cases, the two layers model of Wolfshtein [12] has been used in order to treat the near-wall region. As the flow is very anisotropic, a non linear quadratic $k-\varepsilon$ model has been used to account for the anisotropy of the jet impingement. Figure 7 shows a comparison of the three cases (Table 2) which have been modelled. In all cases, the numerical simulation seems to be showing the same trend as that of the experimental data. 


\section{Sensitivity to the grid}

The sensitivity of calculation to the grid was tested by taking a case test (case 1 - see Table 2). The conditions are the same ones as before, the grid is refined along axis z (20 meshes on a $3 \mathrm{~mm}$ thickness). One does not notice notorious improvement (see Fig. 8) so we have conserved the first grid.

\section{Sensitivity to temporal discretization}

Implicit scheme has been first tested with a time discretization equal to $5.10^{-3} \mathrm{~s}$. Using a second order scheme (Crank-Nicholson) implies the use of a shorter time discretization $\left(5.10^{-4} \mathrm{~s}\right)$ because of a possible numerical diffusion error. The results are slightly improved (Fig. 9).

\section{Sensitivity to near wall treatment}

The first model tested was that of Wolfshtein [12] but it appears that the model of Norris et al. [13] although a little less sophisticated either more robust to treat correctly our case (Fig. 10).

Finally, the comparison between experimental and numerical data tend to confirm the validity of the numerical model used in the flow field simulation for the water jet impinging a moving wall (Fig. 11)

\section{Concluding remarks}

Experimental and numerical investigations were carried out on impinging jet on a moving plate for various jet and plate velocities as well as for various nozzle diameters and heights. The position of the hydraulic jump has been measured thanks to visualizations. A power 
relation has been derived for calculating the radius of the jump in which the Reynolds and Weber numbers take place even if it appears that the main parameters are the dimensionless velocity and the dimensionless height. For industrial purposes involving this kind of flow, it is useful to well predict local heat and mass transfer coefficients which result from this complicated boundary layer flows. Turbulence modelling based on a k-e model and near wall treatment has shown that quantitative results are quite good compared to the experimental ones. Finally this paper shows that the prediction of heat surface coefficient by CFD calculations can be possible with some cautions.

\section{References}

[1] E.J. Watson, 1964, The radial spread of a liquid jet over a horizontal plane, Journal of Fluid Mech., 20, 481-495

[2] V.E. Nakoryakov, B.G. Pokusaev and E.N. Troyan, 1978, Impingement of an axisymmetric liquid jet on a barrier, Int. J. Heat Mass Transfer, 21, 1175-1184

[3] T. Azuma and T. Hoshino, 1984, The radial flow of thin liquid film, Trans. Japan Mech. Engrs., 50, 974-1136

[4] J. Stevens and B.W. Webb,1993, Measurements of flow structure in the radial layer of impinging free-surface liquid jets, Int. J. Heat Mass Transfer, $36 \mathrm{n}^{\circ} 15,3751-3758$

[5] YU. A. Buyevitch and V.A. Ustinov, 1994, Hydrodynamic conditions of transfer processes through a radial jet spreading over a flat surface, Int. J. Heat Mass Transfer, $37 \mathrm{n}^{\circ} 1,165-173$

[6] Y. Pan, J. Stevens and B.W. Webb, 1992, Effect of nozzle configuration on transport in the stagnation zone of axisymmetric, impinging free-surface liquid jets: part 2Local heat transfer, Journal of Heat Transfer, 114, 880-886 
[7] T. Bohr, P. Dimon and V. Putkaradze, 1993, Shallow water approach to the circular hydraulic jump, J. Fluid Mech., 254, 635-648.

[8] D. A. Zumbrunnen, 1991, Convective heat and mass transfer in the stagnation region of a laminar planar jet impinging on a moving surface, J. of Heat Transfer, 113, 563570

[9] D. A. Zumbrunnen,, F.P. Incropera and R. Viskanta, 1992, A laminar boundary layer model of heat transfer due to a nonuniform planar jet impinging on a moving plate, Wärme und Stoffübertragung, 27, 311-319

[10] H. Chattopadhyay and S.K. Saha, 2003, Turbulent flow and heat transfer from a slot jet impinging on a moving plate, Int. Journal of Heat and Fluid Flow, 24, 685-697

[11] C.W. Hirt and B.D. Nichols, 1981, Volume of fluid (VOF) method for the dynamics of free boundaries, J. Comput. Phys., 39, 201-225

[12] M. Wolfshtein, 1969, The velocity and temperature distribution of one dimensional flow with turbulence augmentation and pressure gradient, Int. J. Heat Mass Transfer, $12,301-318$

[13] L.H Norris and W.C Reynolds, 1975, Turbulent channel flow with a moving wavy boundary, Report No.FM-10, Dpt of Mechanical Engineering, Stanford University. 


\begin{tabular}{|c|cccc|}
\hline Jet velocity & \multicolumn{4}{|c|}{ Moving strip velocity } \\
\hline $2.17 \mathrm{~m} / \mathrm{s}$ & $2.65 \mathrm{~m} / \mathrm{s}$ & $1.99 \mathrm{~m} / \mathrm{s}$ & \\
\hline $1.4 \mathrm{~m} / \mathrm{s}$ & $2.35 \mathrm{~m} / \mathrm{s}$ & $2.04 \mathrm{~m} / \mathrm{s}$ & $1.53 \mathrm{~m} / \mathrm{s}$ & $1.02 \mathrm{~m} / \mathrm{s}$ \\
\hline $1 \mathrm{~m} / \mathrm{s}$ & $2.35 \mathrm{~m} / \mathrm{s}$ & $2.04 \mathrm{~m} / \mathrm{s}$ & $1.53 \mathrm{~m} / \mathrm{s}$ & $1.02 \mathrm{~m} / \mathrm{s}$ \\
\hline $0.41 \mathrm{~m} / \mathrm{s}$ & $2.04 \mathrm{~m} / \mathrm{s}$ & $1.53 \mathrm{~m} / \mathrm{s}$ & $1.02 \mathrm{~m} / \mathrm{s}$ & $0.51 \mathrm{~m} / \mathrm{s}$ \\
\hline
\end{tabular}

Table 1 : test conditions 


\begin{tabular}{|l|c|c|c|c|c|c|c|c|c|c|}
\cline { 2 - 11 } \multicolumn{1}{c|}{} & $\bar{V}_{S}$ & $\begin{array}{c}V_{j} \\
(\mathrm{~m} / \mathrm{s})\end{array}$ & $\begin{array}{c}V_{j \text { simu }} \\
(\mathrm{m} / \mathrm{s})\end{array}$ & $\begin{array}{c}V_{S} \\
(\mathrm{~m} / \mathrm{s})\end{array}$ & $\begin{array}{c}D \\
(\mathrm{~mm})\end{array}$ & $\begin{array}{c}D_{j \text { simu }} \\
(\mathrm{mm})\end{array}$ & $\begin{array}{c}D \\
(\mathrm{~mm})\end{array}$ & $\begin{array}{c}H \\
(\mathrm{~mm})\end{array}$ & $\begin{array}{c}h_{\text {simu }} \\
(\mathrm{mm})\end{array}$ & $\begin{array}{c}V_{I} \\
(\mathrm{~m} / \mathrm{s})\end{array}$ \\
\hline Case 1 & 5.1 & 0.41 & 1.46 & 2.04 & 17 & 9 & 8.2 & 150 & 50 & 1.76 \\
\hline Case 2 & 1.53 & 1 & 1.72 & 1.53 & 17 & 12.96 & 12.06 & 150 & 50 & 1.99 \\
\hline Case 3 & 1.02 & 1 & 1.72 & 1.02 & 17 & 12.96 & 12.06 & 150 & 50 & 1.99 \\
\cline { 2 - 11 }
\end{tabular}

Table 2 : parameters of the flow simulation 

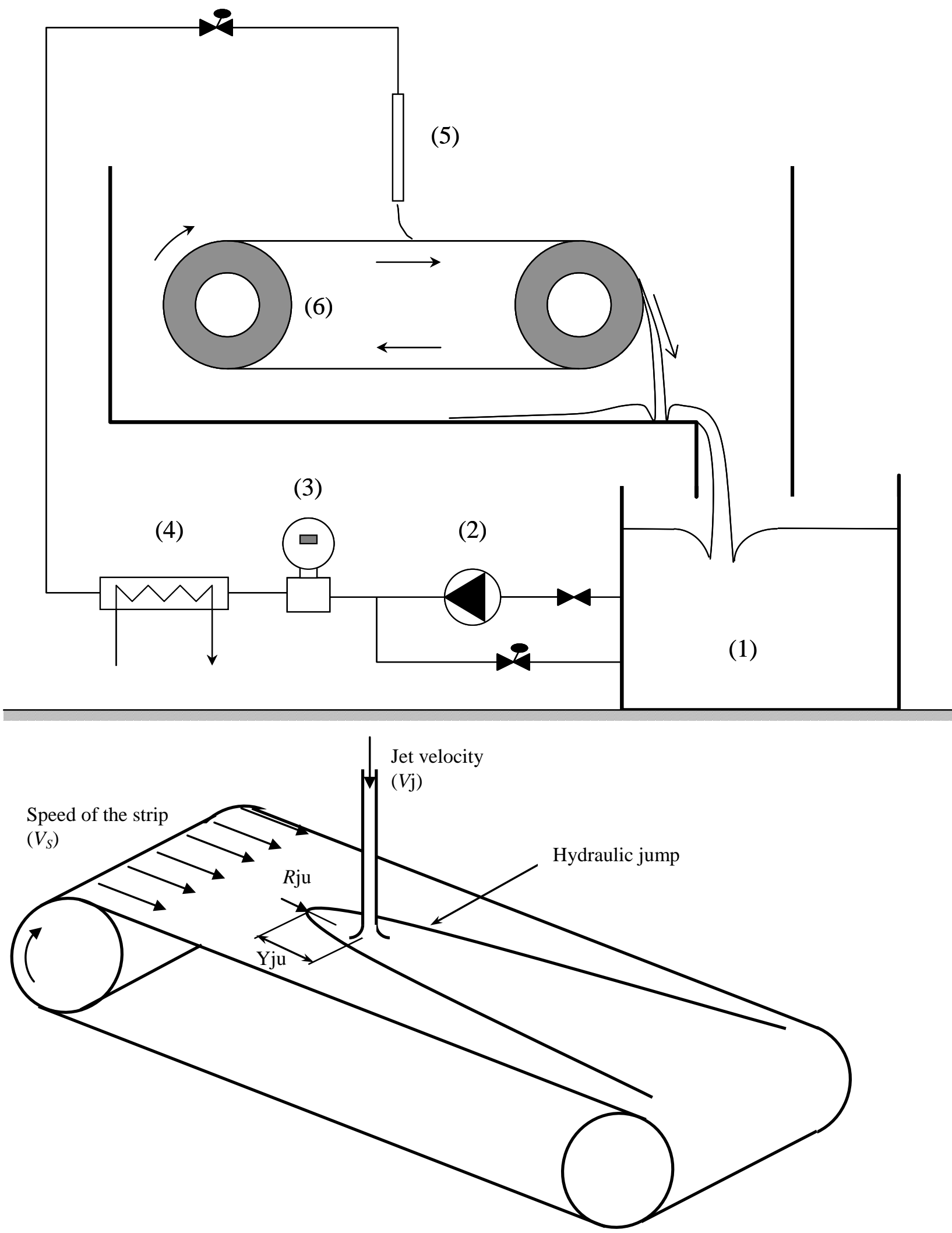

Figure 1 : scheme of the flow loop 


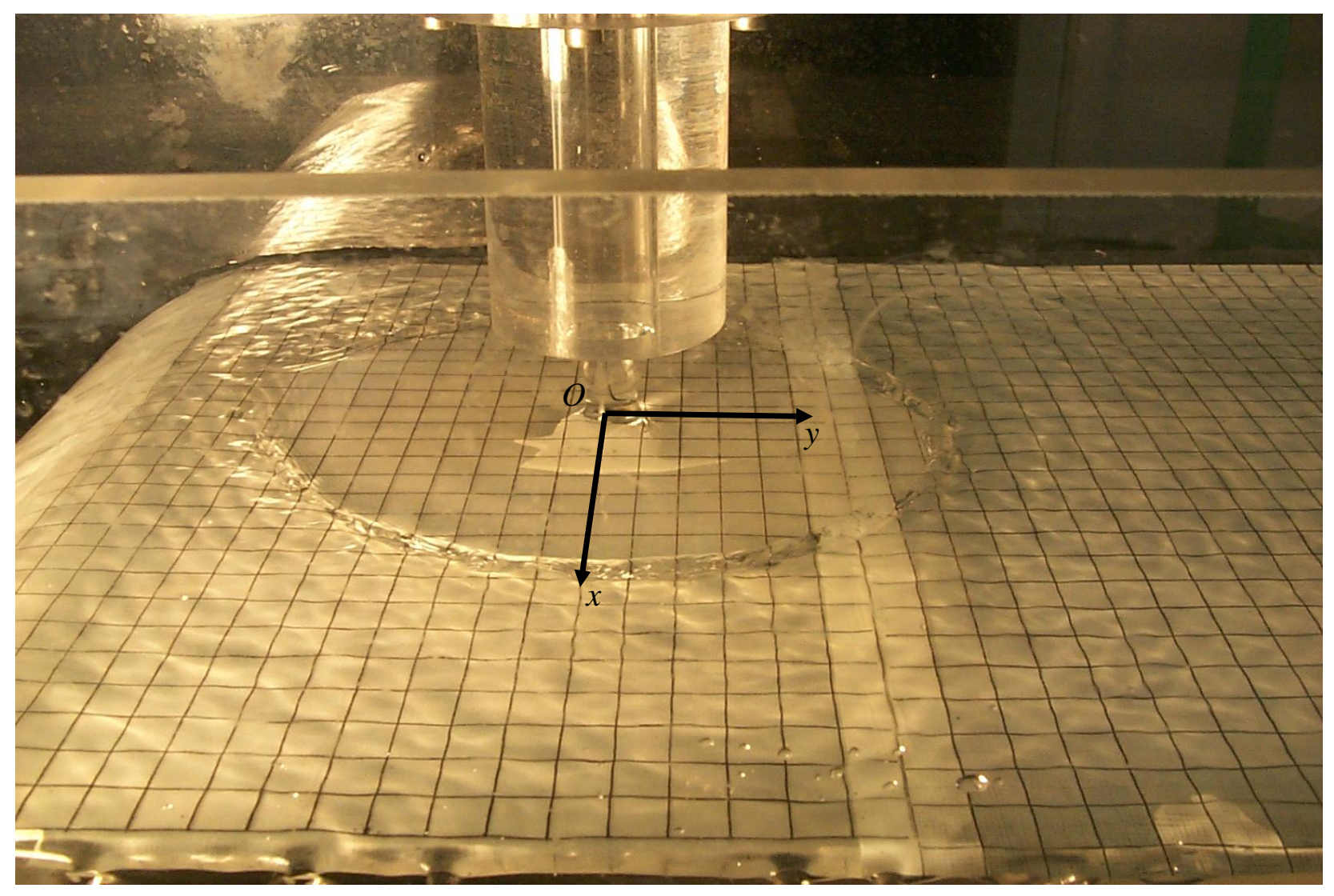

Figure 2 : example of "grid" picture and hydraulic jump pattern recognition 

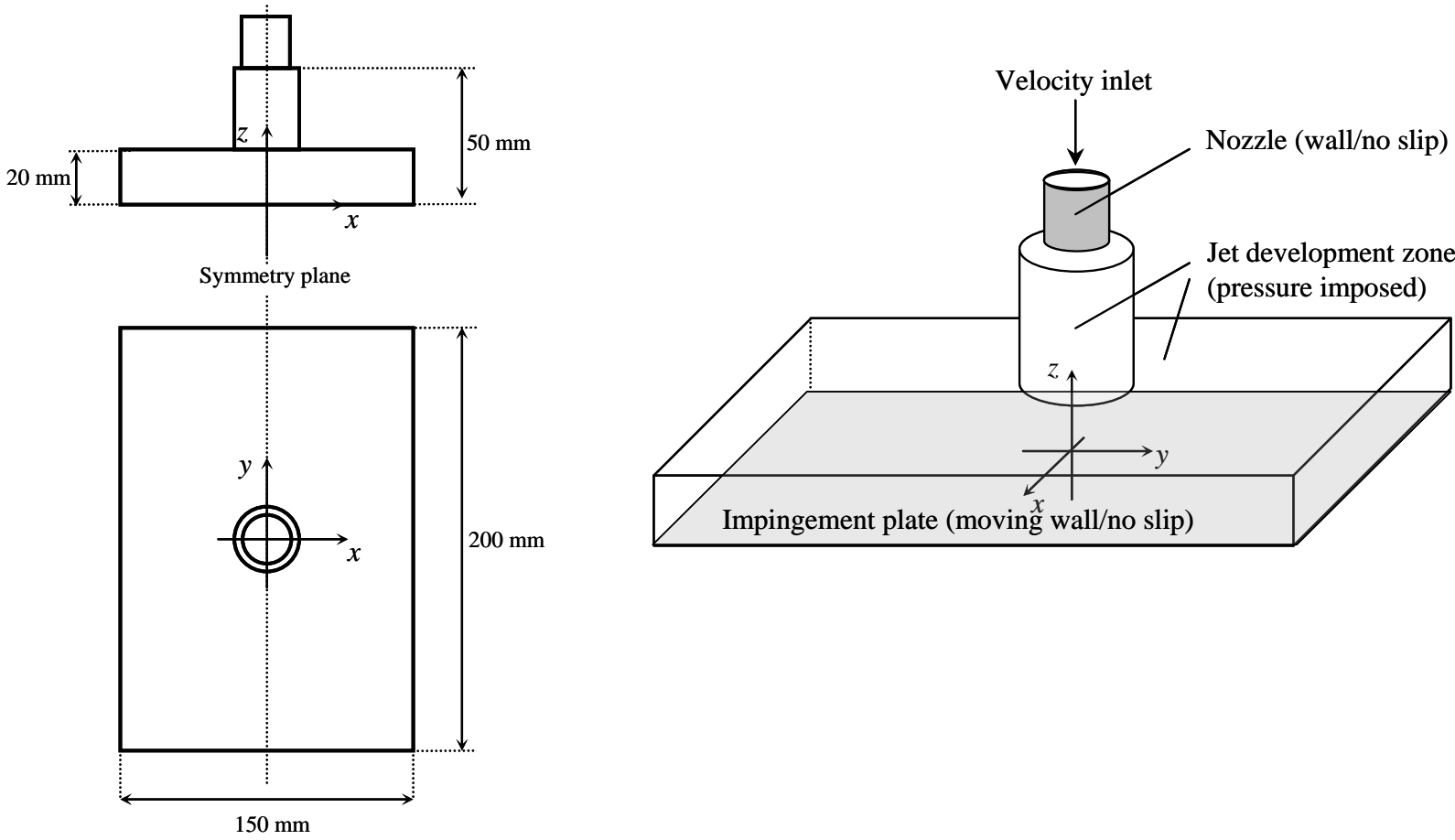

Figure $3 \mathrm{a}$ : calculation domain and the associated boundary conditions

non uniform grid
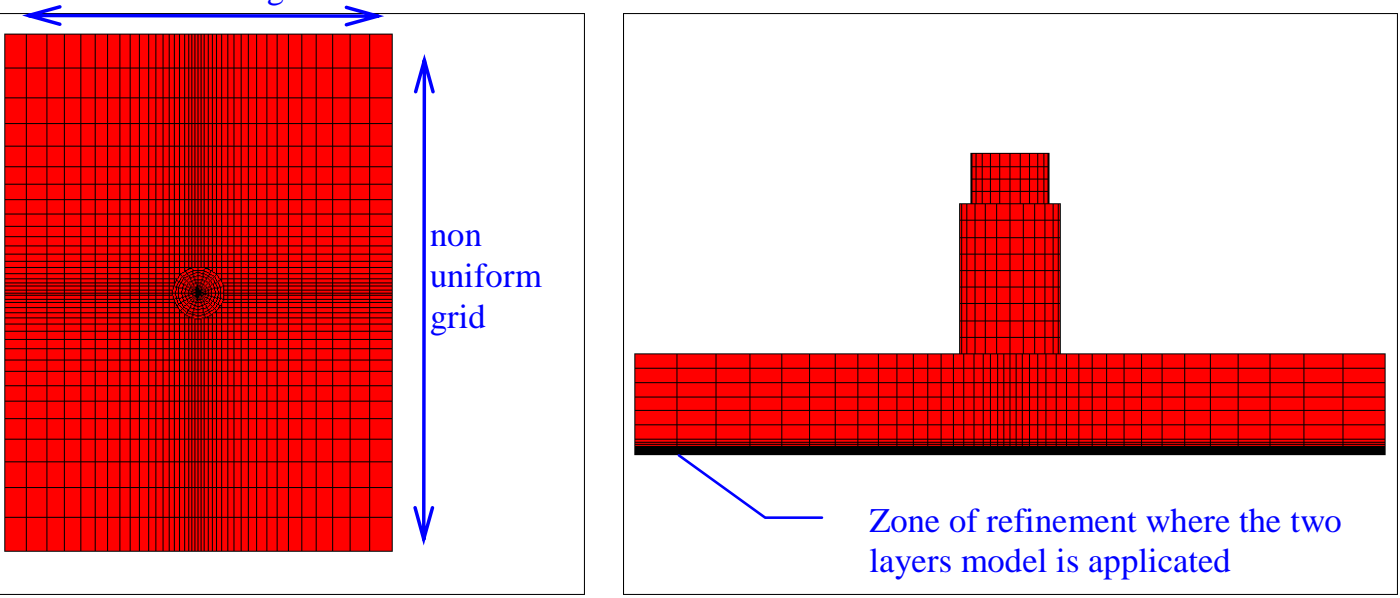

Figure $3 b$ : grid 

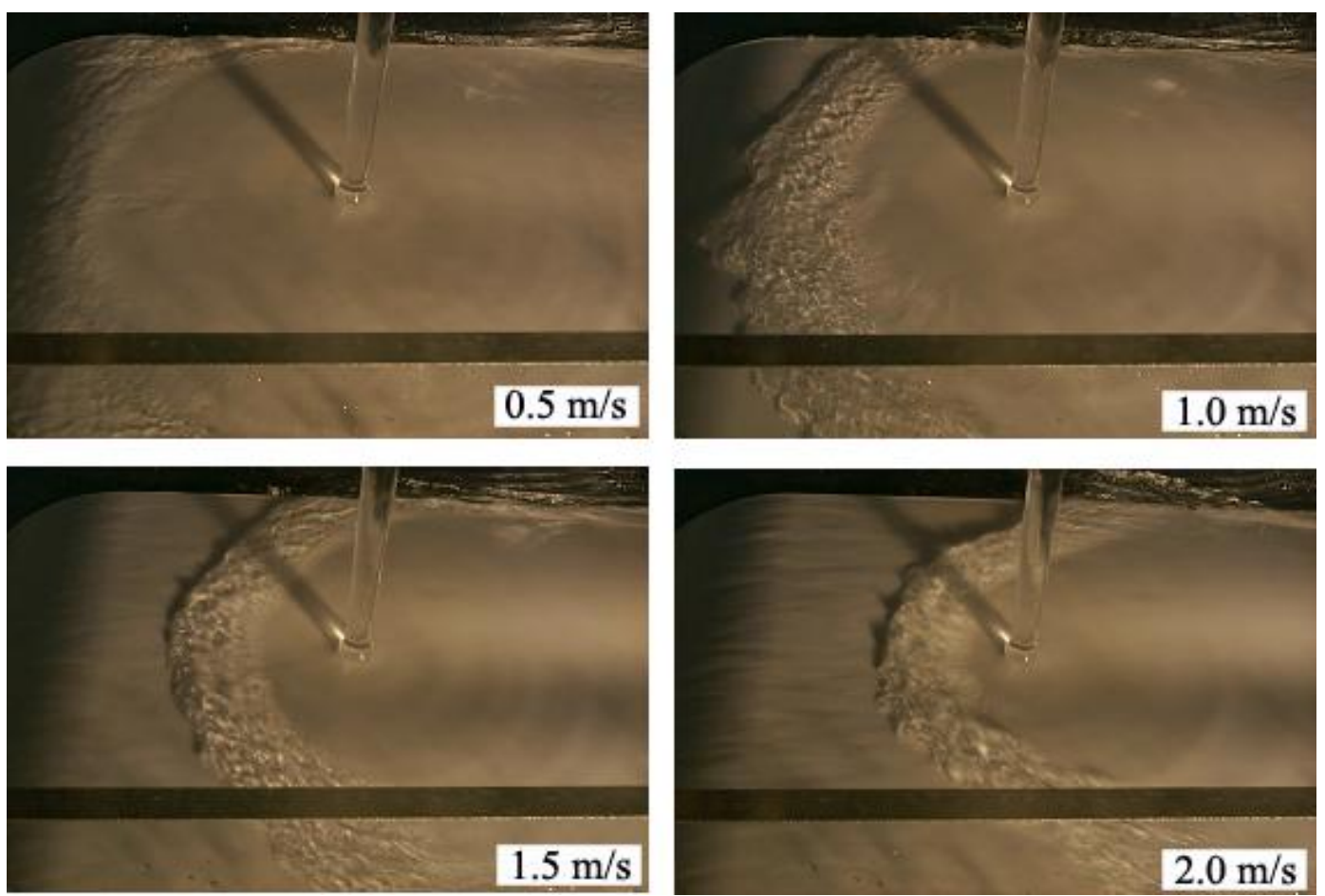

Figure 4 : hydraulic jump visualizations for different surface velocities

$$
V_{j}=1 \mathrm{~m} / \mathrm{s} \text { and } \bar{H}=0.11
$$



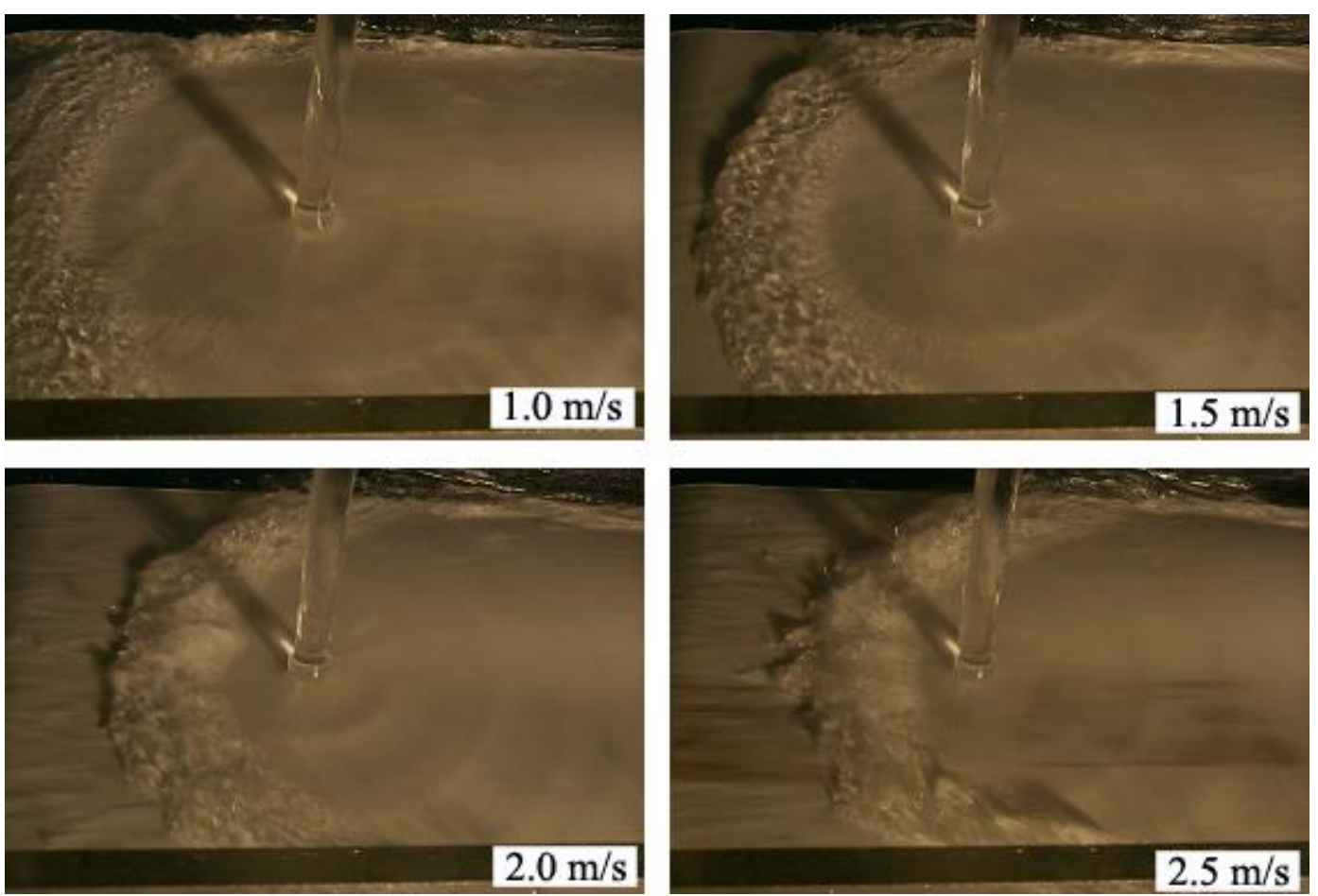

Figure 5 : hydraulic jump visualizations for different surface velocities

$$
V_{j}=1.4 \mathrm{~m} / \mathrm{s} \text { and } \bar{H}=0.11
$$




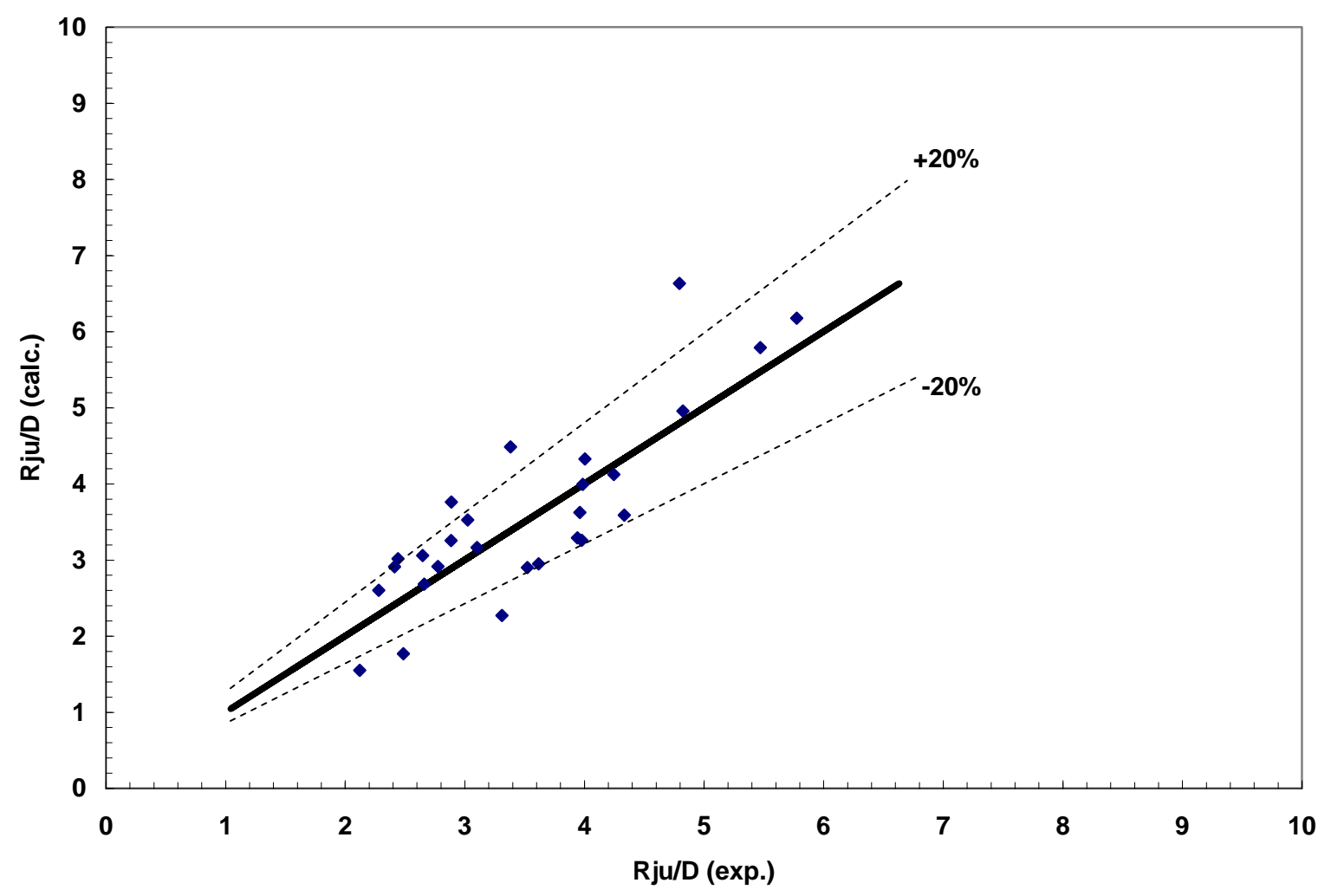

Figure 6: Comparison of the experimental radius of the jump with that calculated by Eq. (6) 


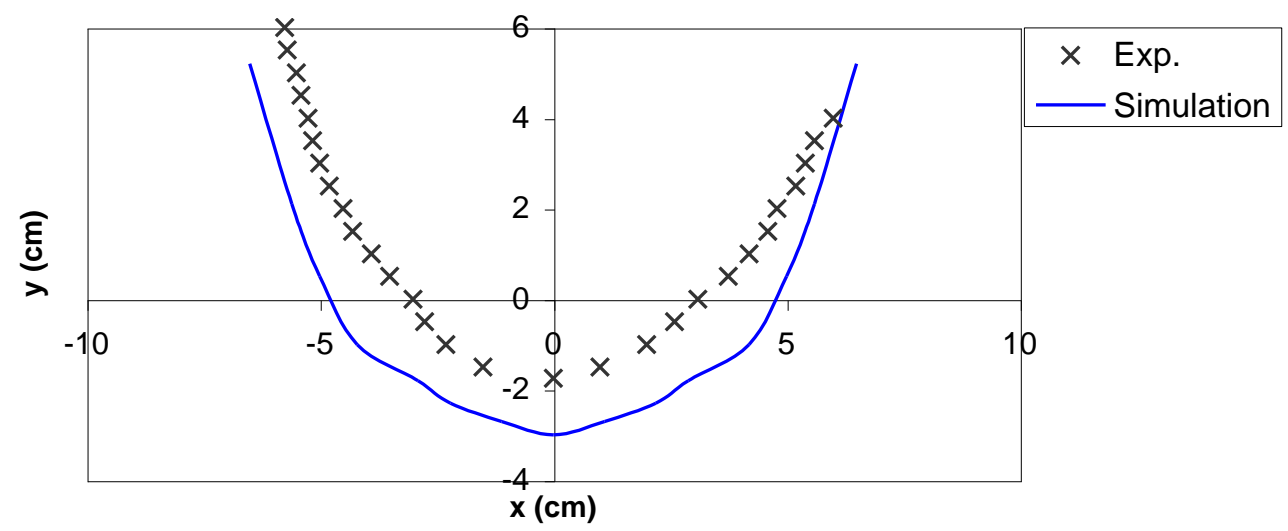

Figure 7a : jump position $-V_{J}=0,41 \mathrm{~m} / \mathrm{s}$ and $V_{S}=2,04 \mathrm{~m} / \mathrm{s} \rightarrow \overline{V_{S}}=5.1$

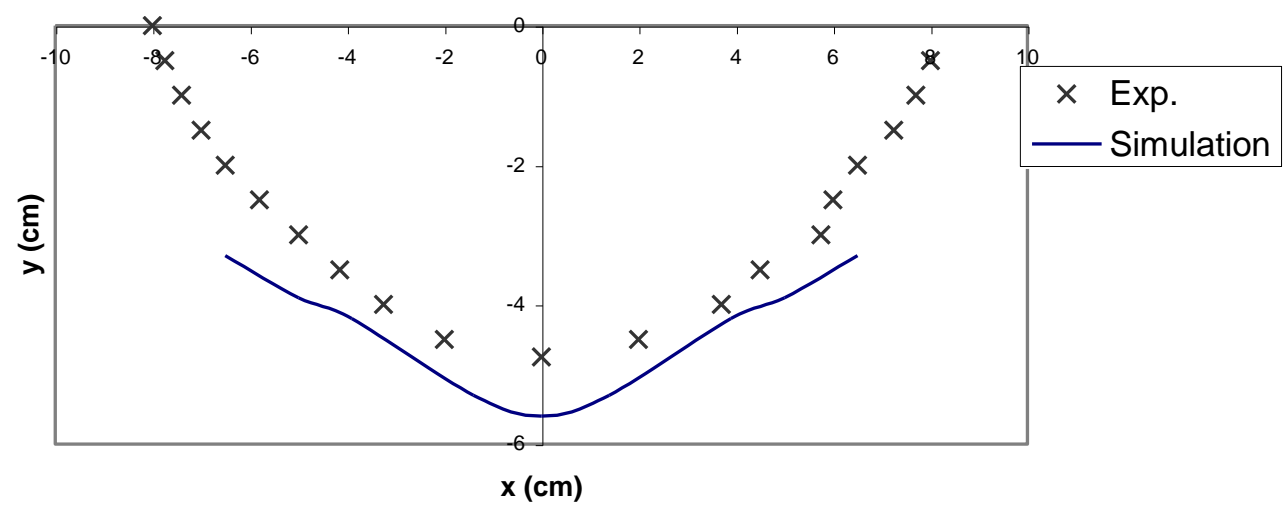

Figure $7 \mathrm{~b}:$ jump position $-V_{J}=1 \mathrm{~m} / \mathrm{s}$ and $V_{S}=1.53 \mathrm{~m} / \mathrm{s} \rightarrow \overline{V_{S}}=1.53$

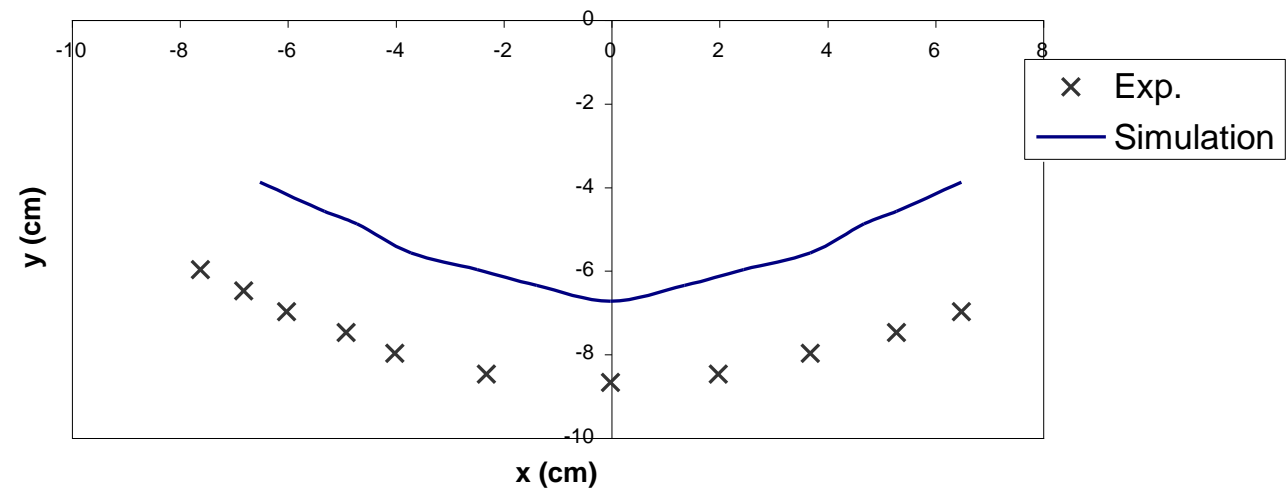

Figure $7 \mathrm{c}:$ jump position $-V_{J}=1 \mathrm{~m} / \mathrm{s}$ and $V_{S}=1.02 \mathrm{~m} / \mathrm{s} \rightarrow \overline{V_{S}}=1.02$ 


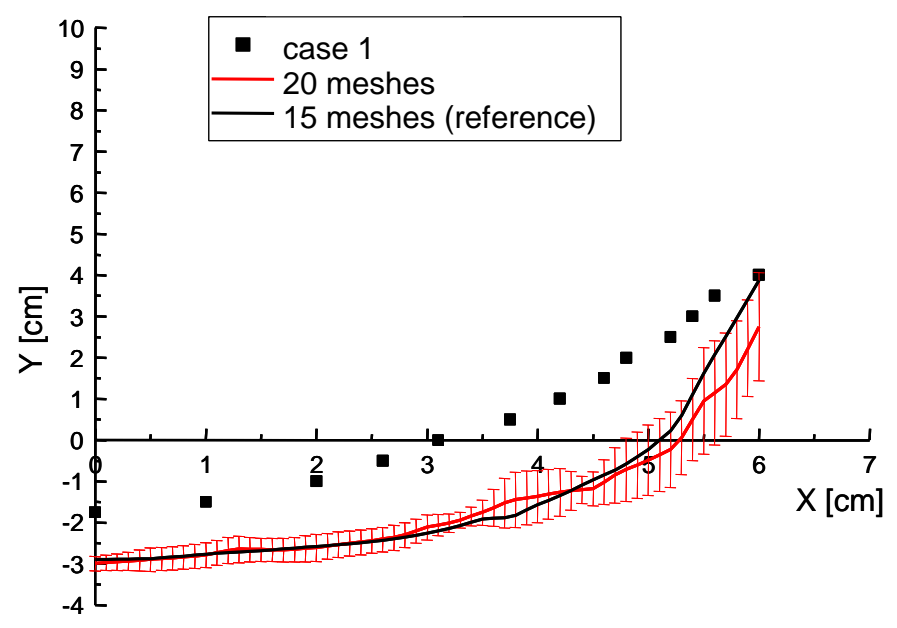

Figure 8 : grid sensitivity

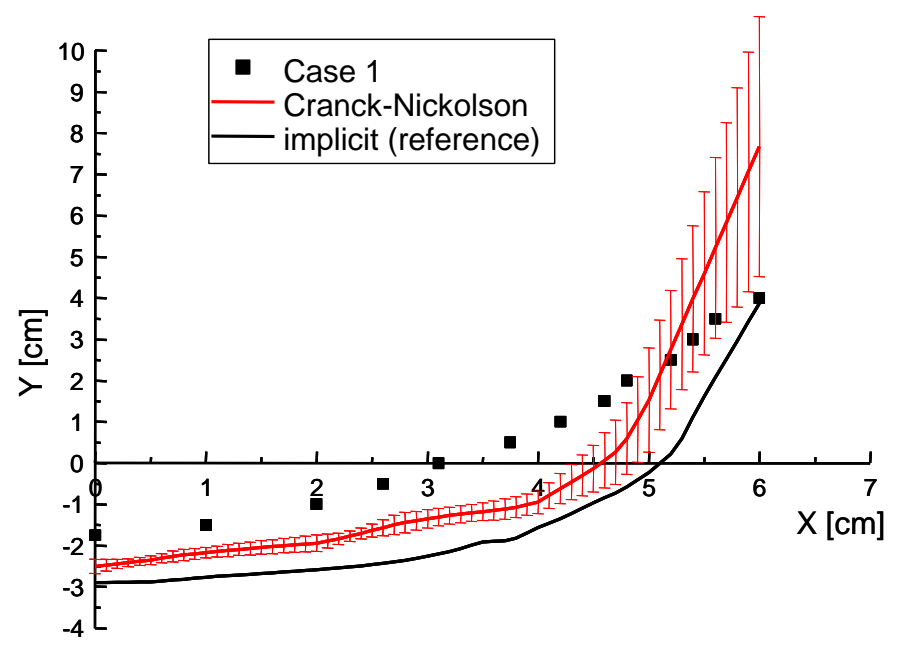

Figure 9 : temporal scheme sensitivity 


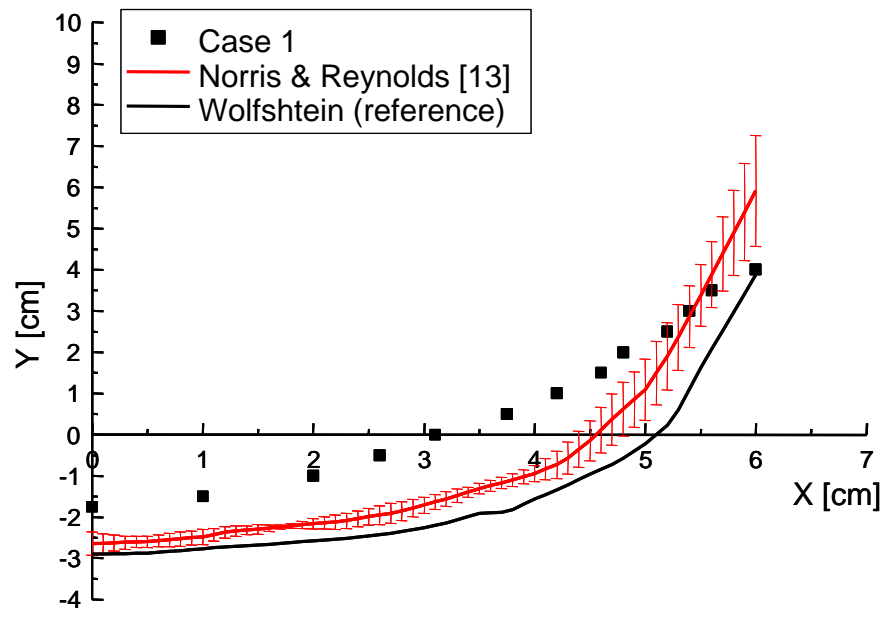

Figure 10 : near wall treatment sensitivity

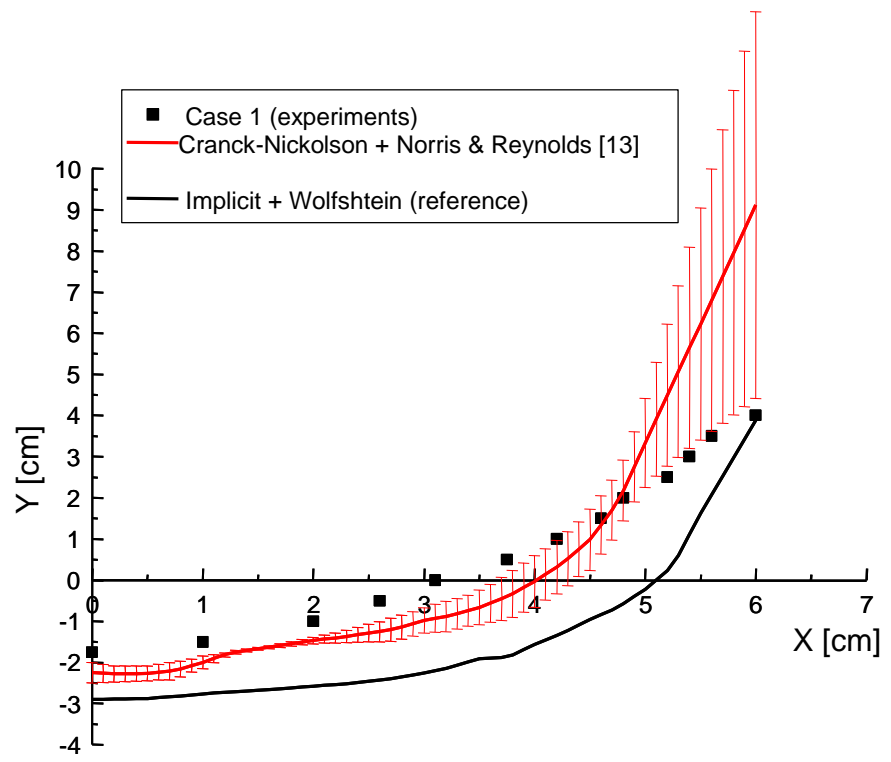

Figure 11 : final parameters choice 